\title{
Healing for destruction: tRNA intron degradation in yeast is a two-step cytoplasmic process catalyzed by tRNA ligase Rlg1 and $5^{\prime}$-to-3' exonuclease Xrn1
}

\begin{abstract}
Jingyan $\mathrm{Wu}^{1,2,3}$ and Anita K. Hopper ${ }^{1,3,4}$
${ }^{1}$ Department of Molecular Genetics, ${ }^{2}$ Graduate Program in Plant Cellular and Molecular Biology, ${ }^{3}$ Center for RNA Biology, The Ohio State University, Columbus, Ohio 43210, USA

In eukaryotes and archaea, tRNA splicing generates free intron molecules. Although $\sim \mathbf{6 0 0 , 0 0 0}$ introns are produced per generation in yeast, they are barely detectable in cells, indicating efficient turnover of introns. Through a genome-wide search for genes involved in tRNA biology in yeast, we uncovered the mechanism for intron turnover. This process requires healing of the 5 ' termini of linear introns by the tRNA ligase Rlg1 and destruction by the cytoplasmic tRNA quality control 5'-to-3' exonuclease Xrn1, which has specificity for RNAs with 5' monophosphate.
\end{abstract}

Supplemental material is available for this article.

Received May 2, 2014; revised version accepted June 3, 2014.

tRNAs are essential for translation in all kingdoms of life. In addition, tRNAs play important roles in other cellular events, such as protein degradation, apoptosis, cellular response to stress, and cancer (Phizicky and Hopper 2010). tRNA biogenesis involves numerous post-transcriptional processes, including removal of $5^{\prime}$ leaders and $3^{\prime}$ trailers, addition of 3' CCA nucleotides and nucleoside modifications, and, for tRNAs encoded by intron-containing genes, splicing of introns (Phizicky and Hopper 2010).

Splicing of introns is essential for cells to generate complete sets of tRNAs to decode all codons. The percentage of tRNA genes that harbor introns varies significantly, from $0 \%$ in bacteria to $5 \%$ in mice and humans to $>60 \%$ in some archaea (Genomic tRNA Database, http://lowelab.ucsc.edu/ GtRNAdb). In yeast Saccharomyces cerevisiae, 59 (21.5\%) of 274 tRNA genes from 10 different isodecoder tRNA families contain an intron (Phizicky and Hopper 2010).

In yeast and vertebrates, tRNA splicing is catalyzed by the heterotetrameric tRNA splicing endonuclease (SEN) complex, yielding the $5^{\prime}$ half with a $2^{\prime}, 3^{\prime}$-cyclic phosphate, the intron with a $5^{\prime}$ hydroxyl and 2', 3'-cyclic phosphate, and the $3^{\prime}$ half with a $5^{\prime}$ hydroxyl (Knapp et al. 1979; Trotta et al. 1997; Paushkin et al. 2004). In vertebrates, tRNA splicing occurs in the nucleus (Melton et al. 1980; Lund and Dahlberg 1998; Paushkin et al. 2004), whereas it is

[Keywords: tRNA splicing; tRNA ligation; intron turnover; Xrn1; Rlg1; $5^{\prime}$ to $3^{\prime}$ exonuclease]

${ }^{4}$ Corresponding author

E-mail hopper.64@osu.edu

Article is online at http://www.genesdev.org/cgi/doi/10.1101/gad.244673.114. a cytoplasmic process in yeast, since the SEN complex is located on the outer surface of mitochondria (Yoshihisa et al. 2003). Despite the difference in localization, the structure and function of the SEN complex are conserved from yeast to humans (Trotta et al. 1997; Paushkin et al. 2004).

In yeast and plants, after splicing, the $5^{\prime}$ and $3^{\prime}$ halves are ligated through a series of enzymatic reactions that require three activities of the tRNA ligase Rlg1 (Greer et al. 1983; Phizicky et al. 1986; Englert and Beier 2005): (1) a cyclic phosphodiesterase (CPDase) activity that opens the $2^{\prime}, 3^{\prime}$ cyclic phosphate of the $5^{\prime}$ exon, (2) a polynucleotide kinase activity that phosphorylates the $5^{\prime}$ end of the $3^{\prime}$ exon, and (3) an ATP-dependent ligase activity that joins the two exons together. Finally, the 2 -phosphate remaining at the ligation junction is removed by the phosphotransferase Tpt1 (Culver et al. 1993) to form the mature tRNA.

Although much is known about the ligation of two tRNA halves, little is known about the fate of the other splicing product, the free tRNA intron. In contrast to the high abundance of mature tRNAs, free introns are barely detectable, indicating that they are degraded rapidly after splicing. To date, two tRNA degradation pathways have been identified in yeast as tRNA quality control mechanisms. The nuclear surveillance pathway provides one mechanism; pre-tRNA ${ }^{\text {Met }}{ }_{i}$ lacking $\mathrm{m}^{1} \mathrm{~A}_{58}$ and pre-tRNAs with aberrant $3^{\prime}$ ends are polyadenylated by the TRAMP complex and further degraded by the nuclear exosome (Kabada et al. 2004; Copela et al. 2008; Ozanick et al. 2009). The other pathway, the rapid tRNA decay (RTD) pathway, destroys mature tRNAs that lack certain combinations of modifications or tRNAs that bear unstable $\mathrm{T}$ or acceptor stems (Chernyakov et al. 2008; Whipple et al. 2011).

Although turnover pathways for aberrant precursor and mature tRNAs have been studied extensively, little is known about degradation of tRNA introns. Since $\sim 3,000,000$ tRNAs are produced per generation in yeast (Waldron and Lacroute 1975) and $>20 \%$ are intron-containing tRNAs, an enormous amount of tRNA introns $(\sim 600,000)$ is produced during each generation. Cells may need to efficiently degrade tRNA introns to generate nucleotides or prevent introns from interacting with other RNAs and RNA-binding proteins and perhaps inhibiting their functions. There is precedent for this, as cytoplasmic accumulation of mRNA intron lariats in human cells sequesters and suppresses TDP-43, a key factor involved in amyotrophic lateral sclerosis (Armakola et al. 2012).

Here we uncovered the mechanism for tRNA intron decay in yeast. Through a genome-wide screen for novel gene products involved in tRNA biology, we found that tRNA introns accumulate in cells lacking the cytoplasmic RTD 5'-to-3' exonuclease Xrn1. Degradation of introns via Xrn1 requires healing of tRNA intron $5^{\prime}$ termini by the tRNA ligase Rlg1. Neither defects in $3^{\prime}$-to-5' nucleases nor a temperature-sensitive (ts) mutation of the

(C) $2014 \mathrm{Wu}$ and Hopper This article is distributed exclusively by Cold Spring Harbor Laboratory Press for the first six months after the full-issue publication date (see http://genesdev.cshlp.org/site/misc/terms.xhtml). After six months, it is available under a Creative Commons License (Attribution-NonCommercial 4.0 International), as described at http:// creativecommons.org/licenses/by-nc/4.0/. 
nuclear RTD 5' -to-3' exonuclease Rat1 affect tRNA intron turnover. We conclude that tRNA intron decay is a cytoplasmic two-step process that is catalyzed by the $5^{\prime}$-to- 3 ' nuclease Xrn1 and tRNA ligase Rlg1.

\section{Results and Discussion}

\section{The 5'-to-3' exonuclease Xrn1 degrades tRNA introns}

To identify unknown gene products involved in tRNA biogenesis, degradation, and subcellular trafficking, we conducted an unbiased genome-wide screen of yeast genes using the $S$. cerevisiae MATa haploid deletion collection (results of this screen will be presented separately) (Winzeler et al. 1999; Giaever et al. 2002). One of the primary goals of our screen was to identify gene products involved tRNA intron turnover.

To conduct this screen, we assessed the impact of each gene product upon tRNA ${ }^{\text {lle }}$ UAU, which contains the largest tRNA intron (60 nucleotides [nt]) in yeast, by Northern analysis (Wu et al. 2013). We found that cells deleted for $X R N 1$ accumulate high levels of free tRNA ${ }^{\text {Ile }}$ UAU intron compared with wild-type cells. We verified this result using a probe complementary to the nucleotides 1-37 of the $5^{\prime}$ exon and nucleotides $1-30$ of the intron of tRNA $^{\text {Ile }}$ UAU (Fig. 1A [probe 1], B [lanes 1,2]). Similar results were obtained by analysis of xrn1s cells attained from the independent MAT $\alpha$ collection (Fig. 1B, lane 3; Giaever et al. 2002). These results were further confirmed usng another probe (Fig. 1A, probe 2) that hybridizes solely to the 60-nt tRNA ${ }^{\text {Ile }}$ UAU intron (Fig. 1C). Accumulation of introns was suppressed when Xrn1 was exogenously expressed in xrn1s cells from a multicopy plasmid, whereas $x r n 1 \Delta$ cells transformed with vector alone accumulated introns (Fig. 1D, lanes 3,4). We also assessed intron levels for four additional RNAs encoded by tRNA ${ }^{\mathrm{Leu}}{ }_{\mathrm{CAA}}$, tRNA $^{\text {Lys }}{ }_{\text {UUU, }}$ tRNA ${ }^{\text {Trp }}{ }_{C C A}$, and tRNA ${ }^{\text {Pro }}{ }_{\text {UGG genes using }}$ probes complementary solely to the entire intron of each tRNA. Deletion of XRN1 results in accumulation of all tested tRNA introns (Supplemental Fig. S1). Quantitative analysis of the signal intensity of tRNA introns compared with initial transcripts demonstrated 2.5-fold to 11-fold increases in xrn1s cells compared with control cells (Supplemental Fig. S1). These data provide evidence that the 5' -to-3' exonuclease Xrn1 affects tRNA intron turnover in yeast.

\section{5' monophosphorylation is requisite prior to intron degradation by Xrn1}

It is known that Xrn1 specifically hydrolyzes RNA molecules with a 5' monophosphate group (Stevens 1980). However, tRNA splicing generates intron molecules with a 5' hydroxyl group (Knapp et al. 1979). Therefore, we hypothesized that the $5^{\prime}$ termini of nascent spliced introns must be phosphorylated prior to degradation by Xrn1 (Fig. 2A).

To test this hypothesis, we treated total small RNAs isolated from xrn1 $\Delta$ cells with calf intestinal phosphatase (CIP), which catalyzes hydrolysis of 5' phosphate groups from RNA, and/or a Terminator 5'-phosphate-dependent exonuclease (TEX), which specifically degrades RNAs with a single 5' phosphate (Fig. 2A; Patrick et al. 2009). If the $5^{\prime}$ ends of tRNA introns that accumulate in xrn1s cells have a terminal phosphate, CIP treatment could lead to a change in electrophoretic mobility; in contrast, TEX
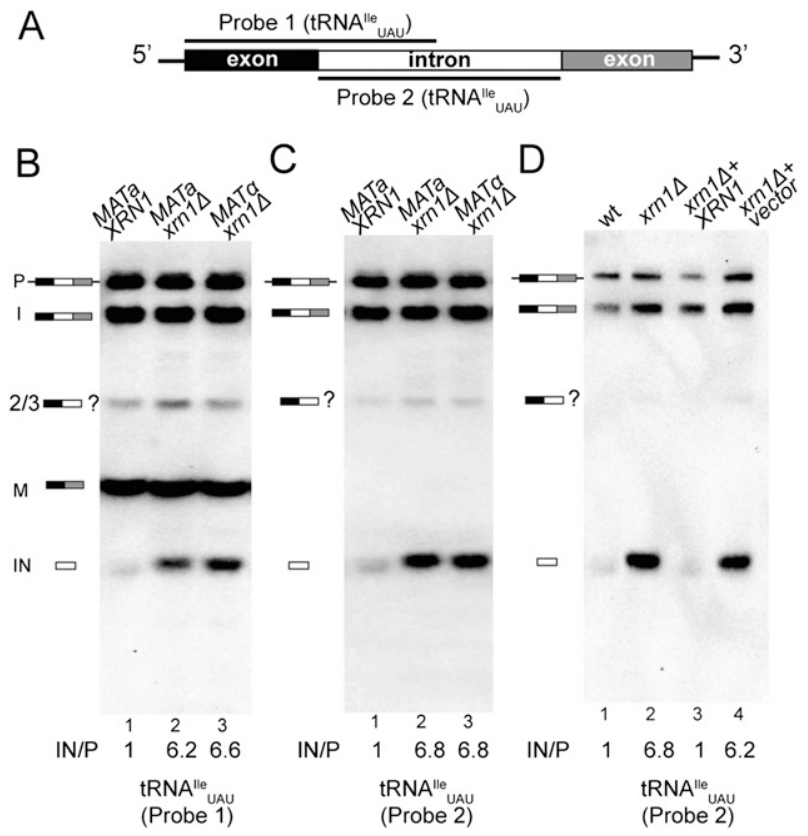

Figure 1. Deletion of the $X R N 1$ gene leads to tRNA intron accumulation. (A) A schematic view of a primary tRNA ${ }_{\text {UAU }}^{\text {Ile }}$ transcript with $5^{\prime}$ leader and $3^{\prime}$ trailer, exons, and an intron and the probes used for Northern hybridization. (B) Two independent xrn1 $1 \Delta$ strains (MATa xrn $1 \Delta$ and MAT $\alpha$ xrn1 1 ) accumulate tRNA ${ }^{\text {Ile }}$ UAU introns. Northern analysis was performed using probe $1 .(C)$ Northern analysis of $M A T a$ wild-type (wt) and two independent xrn1s strains using probe 2. $(D)$ Complementation of the phenotype of xrn1s cells by plasmid encoded Xrn1. Northern analysis of RNAs from MATa wild-type, $x r n 1 \Delta$, and $x r n 1 \Delta$ cells transformed with the multicopy plasmid YEpXrn1 or vector alone were performed using probe 2. Ratios of the signal intensities of introns versus primary tRNA transcripts were calculated and normalized to the wild-type ratio. (P) Primary tRNA transcript (145 nt); (I) end-mature intron containing tRNA (136 nt); (2/3 with a question mark) unknown species, which is likely the $5^{\prime} 2 / 3$ splicing intermediate according to its size (97 nt); (M) mature tRNA (76 nt); (IN) intron (60 nt).

treatment would result in intron degradation. 5.8S rRNA and 5S rRNA, which harbor $5^{\prime}$ monophosphate and triphosphate (Maxam et al. 1977; Henry et al. 1994), respectively, served as positive and negative controls, and their sensitivity/resistance to TEX treatments were as anticipated (Fig. 2B). Treatment of RNAs with CIP resulted in faster migration of the introns (Fig. 2B, lane 2) compared with mock-treated samples (Fig. 2B, lane 1), and TEX treatment resulted in intron degradation (Fig. 2B, lane 3). Introns from samples first treated with CIP to remove the $5^{\prime}$ phosphate were resistant to subsequent degradation by TEX (Fig. 2B, lane 4). Interestingly, end-matured introncontaining pre-tRNAs are resistant to TEX, suggesting that their secondary structure inhibits Terminator exonuclease. Together, the data demonstrate that tRNA introns are $5^{\prime}$ monophosphorylated prior to degradation by Xrn1; these results motivated a search for the kinase that phosphorylates tRNA introns.

\section{The tRNA ligase Rlg1 phosphorylates tRNA introns} prior to degradation by Xrn1

A well-characterized yeast RNA kinase is the tRNA ligase Rlg1. Rlgl contains three enzymatic activities 
A

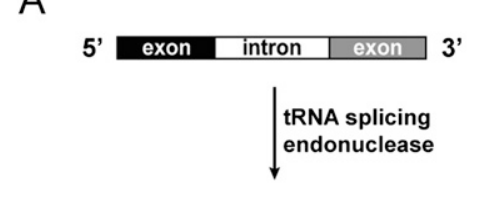

B
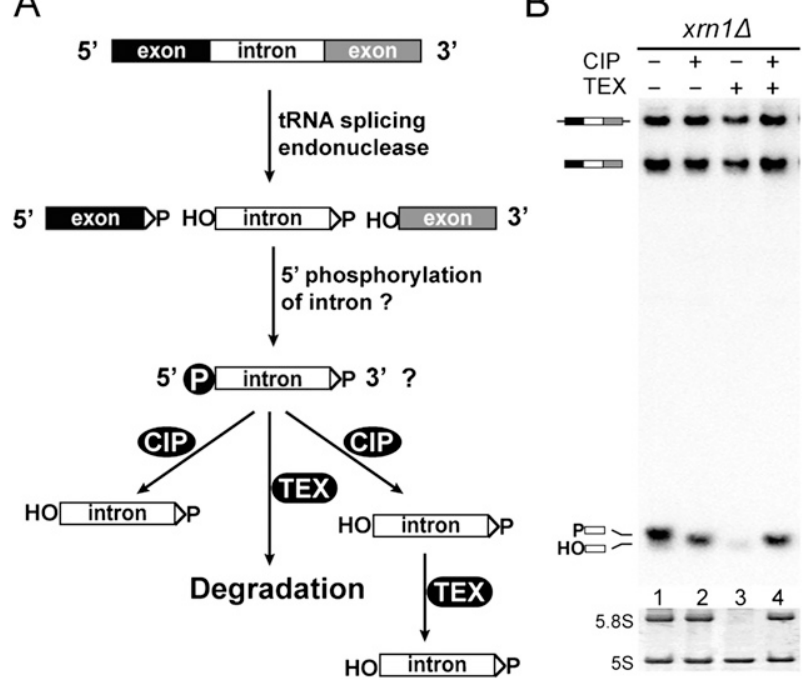

Figure 2. The 5' end of tRNA introns is monophosphorylated prior to degradation by Xrn1. (A) Schematic view of tRNA splicing products and the strategy for determining the $5^{\prime}$ phosphorylation status of introns using CIP and TEX. (B) CIP and TEX treatments. Northern analysis of untreated or treated total small RNAs isolated from xrn1s cells was performed using probe 2. (P, white block) Intron with a $5^{\prime}$ phosphate; (HO, white block) intron with $5^{\prime}$ hydroxyl. $5.8 \mathrm{~S}$ and $5 \mathrm{~S}$ served as controls.

required for tRNA ligation: CPDase, polynucleotide kinase, and ATP-dependent ligase activities. Prior in vitro studies proposed assembly of a SEN-Rlg1 complex for concerted tRNA splicing and ligation (Greer 1986). Moreover, Rlg1 mutant cells were found to accumulate an oligonucleotide of the same size as the tRNA ${ }^{\text {Ile }}$ intron (Phizicky et al. 1992). Therefore, we considered the possibility that free introns generated by SEN splicing may also be substrates of $\mathrm{R} \lg 1$.

If $\mathrm{Rlg} 1$ is required for intron degradation, loss of $R L G 1$ function should cause accumulation of unphosphorylated introns. Since $R L G 1$ is an essential gene for cell viability, there is no $r \lg 1 \Delta$ strain in the yeast deletion collections. We therefore used ts mutants of RLG1, rlg1-4, and rlg1-10 (Phizicky et al. 1992). RNAs isolated from rlg1-4 cells were compared with RNAs from wild-type and xrn1s cells by Northern analysis using two probes, 2 and 3 , which hybridize to the intron and the $5^{\prime}$ exon of tRNA ${ }_{\text {UAU, }}^{\text {Ile }}$ respectively (Fig. 3A; Supplemental Fig. 2A). Two very low abundant species of introns with different mobilities were detected from RNAs isolated from wild-type cells grown at $23^{\circ} \mathrm{C}$ or after a 2 -h shift to $37^{\circ} \mathrm{C}$ (Fig. $3 \mathrm{~B}$, lanes 1,3 ). RNA from rlg1-4 ts cells grown at $23^{\circ} \mathrm{C}$ (Fig. 3B, lane 5) show results similar to wild-type cells, but after a 2-h shift to the nonpermissive temperature $\left(37^{\circ} \mathrm{C}\right)$, there was significant accumulation of tRNA exons (Fig. 3B, lane 7; Supplemental Fig. S2, lane 4), as previously reported (Phizicky et al. 1992). Likewise, tRNAs isolated from rlg1-10 also accumulated tRNA exons (Supplemental Fig. S2B, lane 6). Importantly, both $r \lg 1-4$ and $r \lg 1-10$ also accumulated tRNA introns (Fig. 3B, lane 7; Supplemental Fig. S2B, lanes 4,6 , demonstrating that Rlg1 is required for tRNA intron turnover. In contrast to Xrn1 $1 \Delta$ cells that accumulate the $5^{\prime}$ monophosphorylated introns with slower mobility (Fig. 3B, lanes 9,11), the introns that accumulate in $r \lg 1$ ts mutants had faster mobility (Fig. 3B, lane 7; Supplemental Fig. S2B, lanes 4,6 ), supporting the idea that the introns accumulating in $\operatorname{rg} 1$ ts mutants lack $5^{\prime}$ phosphate.

If Rlg1 phosphorylates introns prior to Xrn1-mediated degradation, the double mutant of RLG1 and XRN1 genes would accumulate unphosphorylated introns. We therefore generated a $r \lg 1-4$ xrn $1 \Delta$ strain. At $23^{\circ} \mathrm{C}$, the $r \lg 1-4$ xrn1s cells (Fig. 3, lane 13) show the same phenotype as xrn1s cells-accumulation of introns with slow mobility. However, after a 2 -h shift to $37^{\circ} \mathrm{C}, \mathrm{rlg} 1-4$ xrn1 $1 \Delta$ cells also accumulate introns with faster mobility (Fig. 3B, lane 15). The data are consistent with the hypothesis that when cells lose $R L G 1$, introns fail to be properly phosphorylated and thus cannot be degraded by Xrn1, supporting the notion that Rlg1 acts upstream of Xrn1 in intron turnover.

To test the hypothesis that loss of RLG1 causes accumulation of introns lacking $5^{\prime}$ phosphate, we performed TEX treatment followed by Northern analysis for RNAs isolated from wild-type, rlg1-4, xrn1s, and rlg1-4 xrn1s cells (Fig. 3). If introns accumulating in rlg1 ts

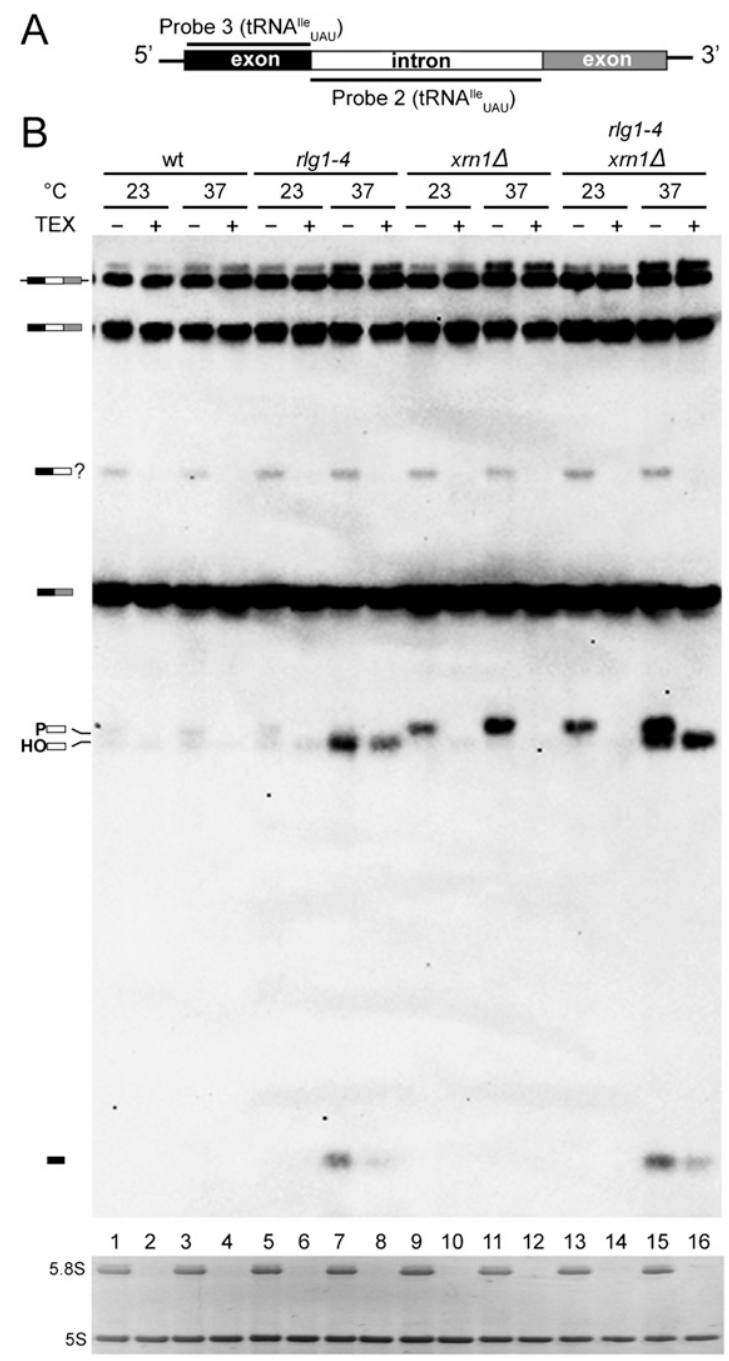

Figure 3. Rlg1 phosphorylates tRNA introns. $(A)$ Probes 3 and 2 were used in the Northern blot shown in $B .(B)$ Northern analysis of TEX-treated and untreated small RNAs from wild-type (wt), rlg1-4, xrn1s, and rlg1-4 xrn1s cells grown at $23^{\circ} \mathrm{C}$ or after a 2-h shift to $37^{\circ} \mathrm{C}$. (Black block) $5^{\prime}$ exon; other symbols are as described in Figures 1 and 2. 5.8S and 5S rRNAs served as controls. 
mutants are unphosphorylated, they would be resistant to TEX treatment. As anticipated, introns accumulating in rlg1-4 cells after a shift to $37^{\circ} \mathrm{C}$ were not degraded by TEX (Fig. 3B, lanes 7,8), whereas introns accumulating in xrn1s cells are degraded (Fig. 3B, lanes 9-12). Similar to introns in $x r n 1 \Delta$ cells, introns accumulating in rlg1-4 xrn $1 \Delta$ cells grown at $23^{\circ} \mathrm{C}$ are also degraded by TEX (Fig. $3 \mathrm{~B}$, lanes 13,14). However, of the two intron species accumulating in rlg1-4 xrn1s cells after shift to $37^{\circ} \mathrm{C}$ (Fig. 3B, lane 15), only the pre-existing monophosphorylated species was sensitive to TEX treatment (Fig. 3B, lane 16). As anticipated, the unstructured $5^{\prime}$ tRNA exons bearing 5 ' monophosphates that accumulate in rlg1-4 and rlg1-4 xrn1s cells upon shift to nonpermissive temperature were degraded by TEX (Fig. 3B, lanes 7,8,15,16). Together, the data show that loss of RLG1 leads to accumulation of the intron with $5^{\prime}$ hydroxyl, whereas loss of XRN1 causes accumulation of introns with 5' phosphate. These studies provide evidence that Rlg1 possesses the kinase activity that phosphorylates introns prior to recognition and degradation of introns by Xrn1.

We also analyzed introns of four other tRNAs, tRNA $^{\text {Leu }}{ }_{\text {CAA, tRNA }}^{\text {Lys }}$ UUU, tRNA ${ }^{\text {Trp }}{ }_{\text {CCA, and tRNA }}^{\text {Pro }}$ UGG in the rlg1-4 mutant. Loss of RLG1 lead to a fourfold to 15.6-fold increase in intron levels (Supplemental Fig. S1). These data suggest that the Rlg1- and Xrn1-mediated tRNA intron degradation pathway is generally used for all tRNAs.

Prior in vitro studies of Rlgl substrate specificity showed that, in addition to catalyzing ligation of tRNA halves, Rlg1 is able to phosphorylate or ligate the ends of artificial linear RNA substrates (Phizicky et al. 1986; Apostol et al. 1991). Our finding that Rlg1 phosphorylates introns indicates that linear molecules can be the substrates for Rlg1 kinase activity in vivo. On the other hand, the question arises as to whether Rlg1 ligase activity is able to join the intron ends to generate circular introns. $\mathrm{R} \lg 1$ is capable of circularizing artificial substrate in vitro (Phizicky et al. 1986), and stable circular introns formed by $3^{\prime}, 5^{\prime}$-phosphodiester linkage have been reported for certain archaea (Salgia et al. 2003). However, since TEX is able to effectively degrade introns, it would appear that the majority of introns in yeast are linear, although there may be minor pools of circular introns that are beyond our detection level. In addition, we did not detect elevated levels of end-matured intron-containing tRNAs or $2 / 3$ molecules consisting of an exon and an intron in xrn1s cells, indicating that $\mathrm{Rlg} 1$ does not join the spliced introns and exons back together even in the presence of high intron levels, whereas it clearly is able to phosphorylate free introns.

Although yeast and plants use Rlg1 and the 2 ' phosphotransferase Tpt1 for tRNA ligation, vertebrates appear to contain two distinct tRNA ligation pathways: a direct ligation pathway and a yeast-like ligation pathway. In the first, a $3^{\prime}$-to-5' ligase activity is used to directly join the 3 ' phosphate of the $5^{\prime}$ exon to the $5^{\prime}$ hydroxyl of the $3^{\prime}$ exon (Popow et al. 2012). In the second, hClp1, a component of the mammalian SEN complex, catalyzes phosphorylation of the $5^{\prime}$ end of the $3^{\prime}$ exon of tRNAs, although the ligase is not identified (Zillmann et al. 1991; Weitzer and Martinez 2007; Ramirez et al. 2008). New studies reported that CLP1 mutation leads to severe neurodegenerative disease, and fibroblasts from human patients accumulate linear introns with a $5^{\prime}$ hydroxyl, although intron accumulation was not observed in in vitro analy- ses (Karaca et al. 2014; Schaffer et al. 2014). We wonder whether introns are targets of CLP1 in vertebrate cells and whether it is possible that defects in tRNA intron turnover might contribute to the neurological phenotypes caused by CLP1 mutations.

\section{tRNA intron degradation is a $5^{\prime}$-to-3' process in the cytoplasm}

Although the above studies provide evidence that turnover of tRNA introns is a two-step process consisting of healing by Rlg1 followed by 5'-to-3' degradation by Xrn1, they do not eliminate the possibilities that other RNA decay machineries also degrade introns and that this process may occur in other cellular compartments than the cytoplasm. To address these issues, we examined whether Rat1, the nuclear 5'-to-3' exonuclease Xrn1 ortholog (Johnson 1997), affects intron turnover. We used a ts mutant of $R A T 1$, rat1-1 (Li et al. 2011), since $R A T 1$ is an essential gene that is not contained in the deletion collection. Similar to wild type (Fig. 4A, lanes 3,4), rat1-1 fails to accumulate tRNA introns after a 2 -h shift to the nonpermissive temperature $37^{\circ} \mathrm{C}$ (Fig. 4A, lanes 1,2), arguing that tRNA introns are not Rat1 substrates and supporting the notion that tRNA intron degradation is restricted to the cytoplasm in yeast. Since splicing occurs in the nucleus in vertebrates, an intriguing question is: Where does intron degradation occur in vertebrates?

Through our screen of the deletion collection, we found that none of the mutants of the other $5^{\prime}$-to- $3^{\prime}$ or $3^{\prime}-$ to- $5^{\prime}$ RNA decay enzymes accumulated tRNA introns. To verify that they are not involved in tRNA intron turnover, we examined their deletion mutants from the independent MAT $\alpha$ deletion collection (Giaever et al. 2002).

Two other 5' -to-3' RNA decay enzymes, Rail, which is predominantly localized to the nucleus (Xue et al. 2000),

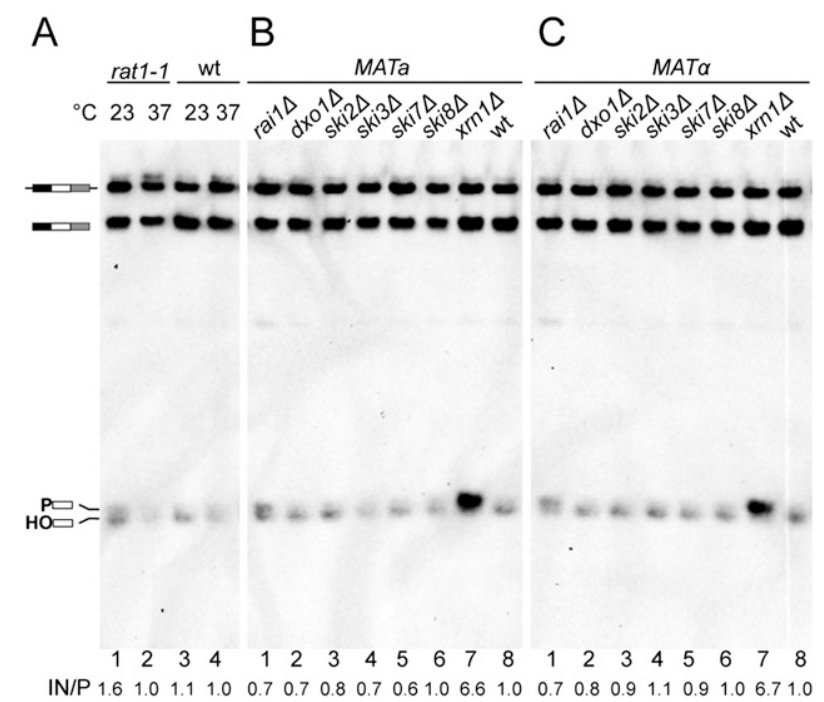

Figure 4. tRNA intron turnover is a $5^{\prime}$-to- $3^{\prime}$ cytoplasmic process. (A) Northern analysis of RNAs from rat1-1 and wild-type (wt) cells grown at $23^{\circ} \mathrm{C}$ or after a shift to $37^{\circ} \mathrm{C}$ using probe 2 . (B) Northern

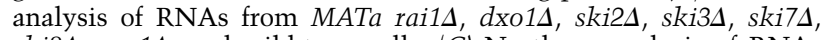
ski8s, xrn1 1 , and wild-type cells. (C) Northern analysis of RNAs

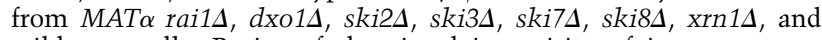
wild-type cells. Ratios of the signal intensities of introns versus primary tRNA transcripts were calculated and normalized to the wild-type ratio. 


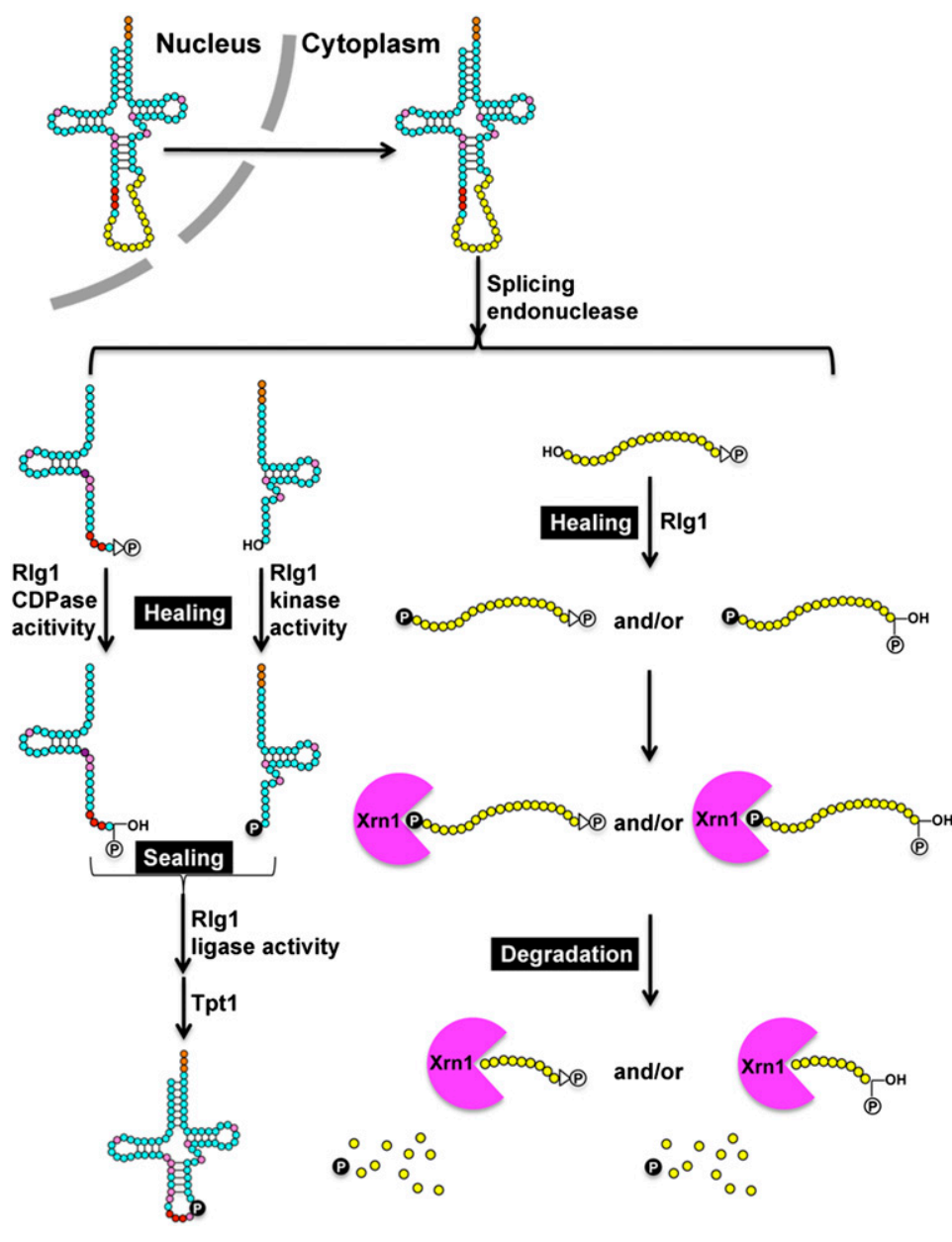

Figure 5. Mechanisms for tRNA splicing, ligation, and intron degradation in yeast. tRNA second structure is illustrated with the following color scheme of circles: exons in light blue, anti-codons in red, introns in yellow, modified nucleotides in pink, and CCA in orange. After nuclear export, end-matured intron-containing tRNAs are spliced by SEN. The CPDase and polynucleotide kinase activity of Rlg1 catalyze healing of the excised ends, and ligase activity catalyzes the sealing of two exons. During intron turnover, the $5^{\prime}$ end of newly spliced introns is phosphorylated by Rlg1, although whether the $3^{\prime}$ end is subjected to Rlg1 CPDase activity is unclear. After Rlg1-mediated phosphorylation, introns are recognized and degraded by Xrn1. lyzed by Xrn1. Assessment of other nuclear or cytoplasmic 5'-to-3' and 3'-to-5' decay pathways provides evidence that intron turnover is a $5^{\prime}$-to- $3^{\prime}$ process in the cytoplasm (Fig. 5).

\section{Materials and methods}

Yeast strains

S. cerevisiae strains in the $M A T a / B Y 4741$ background (MATa

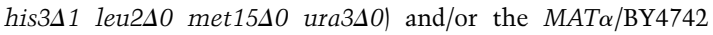

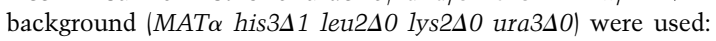

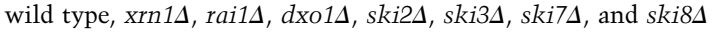
(Open Biosystems). rlg1-4 and rlg1-10 ts strains were previously described (Phizicky et al. 1992). The XRN1 gene was deleted from the $r l g 1-4$ strain by gene replacement with a bacterial hygromycin B resistance gene (Hph) to construct rlg1-4 xrn14. The ts rat1-1 strain was a gift from Dr. Charlie Boone (Li et al. 2011).

\section{CIP treatment}

Twenty micrograms of small RNAs was treated with CIP (New England Biolabs) for $1 \mathrm{~h}$ at $37^{\circ} \mathrm{C}$ according to the manufacturer's protocol. The reaction was terminated by phenol extraction and ethanol precipitation.

\section{TEX treatment}

Ten micrograms of small RNAs was treated with TEX (Epicentre) for $1 \mathrm{~h}$ at $30^{\circ} \mathrm{C}$ according to the manufacturer's protocol. The reaction was terminated by phenol extraction and ethanol precipitation.

\section{Northern analysis}

Small RNAs were isolated by phenol extraction from cultures grown at the permissive temperature $\left(23^{\circ} \mathrm{C}\right)$ to $0.4 \mathrm{OD}_{600}$. The ts mutants were shifted for $2 \mathrm{~h}$ to the nonpermissive temperature $\left(37^{\circ} \mathrm{C}\right)$ before RNA extraction. Seven micrograms of small RNAs was separated by electrophoresis through a $10 \%$ polyacrylamide gel and transferred onto a Hybond $\mathrm{N}^{+}$membrane. tRNAs were detected using DIG-labeled probes as described (Wu et al. 2013). The membranes were exposed to a Lumi-Imager (Boehringer Mannheim), and the signal intensity of each band was quantified as absolute integrated Boehringer light units (BLU) using LumiAnalyst version 3.0 software. and Dxo1, which is primarily cytoplasmic (Chang et al. 2012), were examined. There is no accumulation of tRNA introns in RNAs from $d x o 1 \Delta$ or rai1s cells (Fig. 4B,C, lanes 1,2$)$. We also examined mutations of subunits of the cytoplasmic exosome, the SKI complex (Mitchell and Tollervey 2003). None of the SKI mutants (ski2s, ski3s, ski7s, and ski8s) accumulated tRNA introns (Fig. 4B,C, lanes 3-6). Intron levels of tRNA ${ }^{\mathrm{Leu}}{ }_{\mathrm{CAA}}$ were also examined in all of these mutants, and no accumulation was observed (data not shown). Our data show that the exosome does not contribute to tRNA intron turnover, suggesting that intron turnover may not occur via $3^{\prime}$-to-5' exonucleases.

\section{Conclusions}

Here we report the discovery of the mechanism of intron turnover in yeast (Fig. 5). It is a process catalyzed by a Rlg1-mediated healing step prior to degradation cata-

\section{Oligonucleotides}

The sequences of the oligonucleotides used are provided in the Supplemental Material.

\section{Acknowledgments}

We thank all A.K.H. laboratory members for excellent scientific interactions. We are grateful for the rlg1-4 and rlg1-10 ts mutants and valuable comments from Dr. Eric Phizicky. We also thank Dr. Jane Jackman for inspiring advice on this work. This work was supported by the National Institutes of Health (GM27930 to A.K.H.) and The Ohio State University Pelotonia Graduate Fellowship (to J.W.).

\section{References}

Apostol BL, Westaway SK, Abelson J, Greer CL. 1991. Deletion analysis of a multifunctional yeast tRNA ligase polypeptide. Identification of essential and dispensable functional domains. J Biol Chem 266: 74457455 . 
Armakola M, Higgins MJ, Figley MD, Barmada SJ, Scarborough EA, Diaz Z, Fang X, Shorter J, Krogan NJ, Finkbeiner S, et al. 2012. Inhibition of RNA lariat debranching enzyme suppresses TDP-43 toxicity in ALS disease models. Nat Genet 44: 1302-1309.

Chang JH, Jiao X, Chiba K, Oh C, Martin CE, Kiledjian M, Tong L. 2012. Dxol is a new type of eukaryotic enzyme with both decapping and $5^{\prime}-$ 3' exoribonuclease activity. Nat Struct Mol Biol 19: 1011-1017.

Chernyakov I, Whipple JM, Kotelawala L, Grayhack EJ, Phizicky EM. 2008. Degradation of several hypomodified mature tRNA species in Saccharomyces cerevisiae is mediated by Met 22 and the $5^{\prime}-3^{\prime}$ exonucleases Rat1 and Xrn1. Genes Dev 22: 1369-1380.

Copela LA, Fernandez CF, Sherrer RL, Wolin SL. 2008. Competition between the Rex1 exonuclease and the La protein affects both Trf4pmediated RNA quality control and pre-tRNA maturation. RNA 14: 1214-1227.

Culver GM, McCraith SM, Zillmann M, Kierzek R, Michaud N, LaReau RD, Turner DH, Phizicky EM. 1993. An NAD derivative produced during transfer RNA splicing: ADP-ribose 1"-2" cyclic phosphate. Science 261: 206-208.

Englert M, Beier H. 2005. Plant tRNA ligases are multifunctional enzymes that have diverged in sequence and substrate specificity from RNA ligases of other phylogenetic origins. Nucleic Acids Res 33: 388-399.

Giaever G, Chu AM, Ni L, Connelly C, Riles L, Veronneau S, Dow S, Lucau-Danila A, Anderson K, Andre B, et al. 2002. Functional profiling of the Saccharomyces cerevisiae genome. Nature 418: 387-391.

Greer CL. 1986. Assembly of a tRNA splicing complex: evidence for concerted excision and joining steps in splicing in vitro. Mol Cell Biol 6: $635-644$.

Greer CL, Peebles CL, Gegenheimer P, Abelson J. 1983. Mechanism of action of a yeast RNA ligase in tRNA splicing. Cell 32: 537-546.

Henry Y, Wood H, Morrissey JP, Petfalski E, Kearsey S, Tollervey D. 1994. The $5^{\prime}$ end of yeast $5.8 \mathrm{~S}$ rRNA is generated by exonucleases from an upstream cleavage site. $E M B O J$ 13: 2452-2463.

Johnson AW. 1997. Ratlp and Xrnlp are functionally interchangeable exoribonucleases that are restricted to and required in the nucleus and cytoplasm, respectively. Mol Cell Biol 17: 6122-6130.

Kadaba S, Krueger A, Trice T, Krecic AM, Hinnebusch AG, Anderson J. 2004. Nuclear surveillance and degradation of hypomodified initiator tRNAMet in S. cerevisiae. Genes Dev 18: 1227-1240.

Karaca E, Weitzer S, Pehlivan D, Shiraishi H, Gogakos T, Hanada T, Jhangiani SN, Wiszniewski W, Withers M, Campbell IM, et al. 2014. Human CLP1 mutations alter tRNA biogenesis, affecting both peripheral and central nervous system function. Cell 157: 636-650.

Knapp G, Ogden RC, Peebles CL, Abelson J. 1979. Splicing of yeast tRNA precursors: structure of the reaction intermediates. Cell 18: 37-45.

Li Z, Vizeacoumar FJ, Bahr S, Li J, Warringer J, Vizeacoumar FS, Min R, Vandersluis B, Bellay J, Devit M, et al. 2011. Systematic exploration of essential yeast gene function with temperature-sensitive mutants. Nat Biotechnol 29: 361-367.

Lund E, Dahlberg JE. 1998. Proofreading and aminoacylation of tRNAs before export from the nucleus. Science 282: 2082-2085.

Maxam AM, Tizard R, Skryabin KG, Gilbert W. 1977. Promotor region for yeast 5S ribosomal RNA. Nature 267: 643-645.

Melton DA, De Robertis EM, Cortese R. 1980. Order and intracellular location of the events involved in the maturation of a spliced tRNA. Nature 284: 143-148.

Mitchell P, Tollervey D. 2003. An NMD pathway in yeast involving accelerated deadenylation and exosome-mediated $3^{\prime} \rightarrow 5^{\prime}$ degradation. Mol Cell 11: 1405-1413.

Ozanick SG, Wang X, Costanzo M, Brost RL, Boone C, Anderson JT. 2009. Rexlp deficiency leads to accumulation of precursor initiator tRNAMet and polyadenylation of substrate RNAs in Saccharomyces cerevisiae. Nucleic Acids Res 37: 298-308.

Patrick KL, Shi H, Kolev NG, Ersfeld K, Tschudi C, Ullu E. 2009. Distinct and overlapping roles for two Dicer-like proteins in the RNA interference pathways of the ancient eukaryote Trypanosoma brucei. Proc Natl Acad Sci 106: 17933-17938.

Paushkin SV, Patel M, Furia BS, Peltz SW, Trotta CR. 2004. Identification of a human endonuclease complex reveals a link between tRNA splicing and pre-mRNA 3' end formation. Cell 117: 311-321.
Phizicky EM, Hopper AK. 2010. tRNA biology charges to the front. Genes Dev 24: 1832-1860.

Phizicky EM, Schwartz RC, Abelson J. 1986. Saccharomyces cerevisiae tRNA ligase. Purification of the protein and isolation of the structural gene. J Biol Chem 261: 2978-2986.

Phizicky EM, Consaul SA, Nehrke KW, Abelson J. 1992. Yeast tRNA ligase mutants are nonviable and accumulate tRNA splicing intermediates. J Biol Chem 267: 4577-4582.

Popow J, Schleiffer A, Martinez J. 2012. Diversity and roles of (t)RNA ligases. Cell Mol Life Sci 69: 2657-2670.

Ramirez A, Shuman S, Schwer B. 2008. Human RNA 5'-kinase (hClp1) can function as a tRNA splicing enzyme in vivo. RNA 14: 1737-1745.

Salgia SR, Singh SK, Gurha P, Gupta R. 2003. Two reactions of Haloferax volcanii RNA splicing enzymes: joining of exons and circularization of introns. RNA 9: 319-330.

Schaffer AE, Eggens VR, Caglayan AO, Reuter MS, Scott E, Coufal NG, Silhavy JL, Xue Y, Kayserili H, Yasuno K, et al. 2014. CLP1 founder mutation links tRNA splicing and maturation to cerebellar development and neurodegeneration. Cell 157: 651-663.

Stevens A. 1980. Purification and characterization of a Saccharomyces cerevisiae exoribonuclease which yields $5^{\prime}$-mononucleotides by a $5^{\prime}$ leads to 3' mode of hydrolysis. J Biol Chem 255: 3080-3085.

Trotta CR, Miao F, Arn EA, Stevens SW, Ho CK, Rauhut R, Abelson JN. 1997. The yeast tRNA splicing endonuclease: a tetrameric enzyme with two active site subunits homologous to the archaeal tRNA endonucleases. Cell 89: 849-858.

Waldron C, Lacroute F. 1975. Effect of growth rate on the amounts of ribosomal and transfer ribonucleic acids in yeast. $J$ Bacteriol 122: $855-865$

Weitzer S, Martinez J. 2007. The human RNA kinase hClp1 is active on 3 ' transfer RNA exons and short interfering RNAs. Nature 447: 222226.

Whipple JM, Lane EA, Chernyakov I, D'Silva S, Phizicky EM. 2011. The yeast rapid tRNA decay pathway primarily monitors the structural integrity of the acceptor and T-stems of mature tRNA. Genes Dev 25: 1173-1184.

Winzeler EA, Shoemaker DD, Astromoff A, Liang H, Anderson K, Andre B, Bangham R, Benito R, Boeke JD, Bussey H, et al. 1999. Functional characterization of the $S$. cerevisiae genome by gene deletion and parallel analysis. Science 285: 901-906.

Wu J, Huang HY, Hopper AK. 2013. A rapid and sensitive non-radioactive method applicable for genome-wide analysis of Saccharomyces cerevisiae genes involved in small RNA biology. Yeast 30: 119-128.

Xue Y, Bai X, Lee I, Kallstrom G, Ho J, Brown J, Stevens A, Johnson AW. 2000. Saccharomyces cerevisiae RAIl (YGL246c) is homologous to human DOM3Z and encodes a protein that binds the nuclear exoribonuclease Rat1p. Mol Cell Biol 20: 4006-4015.

Yoshihisa T, Yunoki-Esaki K, Ohshima C, Tanaka N, Endo T. 2003. Possibility of cytoplasmic pre-tRNA splicing: the yeast tRNA splicing endonuclease mainly localizes on the mitochondria. Mol Biol Cell 14: 3266-3279.

Zillmann M, Gorovsky MA, Phizicky EM. 1991. Conserved mechanism of tRNA splicing in eukaryotes. Mol Cell Biol 11: 5410-5416. 


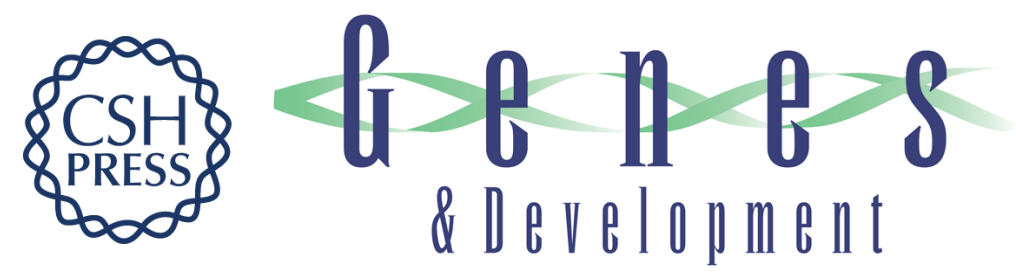

\section{Healing for destruction: tRNA intron degradation in yeast is a two-step cytoplasmic process catalyzed by tRNA ligase RIg1 and 5 '-to-3' exonuclease Xrn1}

Jingyan Wu and Anita K. Hopper

Genes Dev. 2014, 28:

Access the most recent version at doi:10.1101/gad.244673.114

\section{Supplemental} Material

References

Creative

Commons

License

Email Alerting

Service
http://genesdev.cshlp.org/content/suppl/2014/07/16/28.14.1556.DC1

This article cites 40 articles, 21 of which can be accessed free at: http://genesdev.cshlp.org/content/28/14/1556.full.html\#ref-list-1

This article is distributed exclusively by Cold Spring Harbor Laboratory Press for the first six months after the full-issue publication date (see http://genesdev.cshlp.org/site/misc/terms.xhtml). After six months, it is available under a Creative Commons License (Attribution-NonCommercial 4.0 International), as described at http://creativecommons.org/licenses/by-nc/4.0/.

Receive free email alerts when new articles cite this article - sign up in the box at the top right corner of the article or click here.

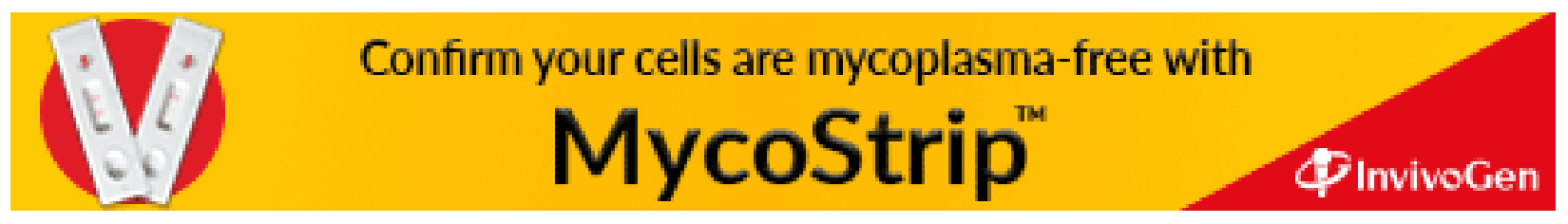

